Supporting Information for

\title{
Sacrificial template synthesis and properties of 3-D hollow-silicon nano- and microstructures
}

\author{
Iris Hölken, ${ }^{\mathbf{1}}$ Gero Neubüser, ${ }^{\mathbf{1}}$ Vasile Postica, ${ }^{\mathbf{2}}$ Lars Bumke, ${ }^{1}$ Oleg Lupan, ${ }^{\mathbf{1}, *}$ \\ Martina Baum, ${ }^{1}$ Yogendra Mishra, ${ }^{1, *}$ Lorenz Kienle, ${ }^{\mathbf{1}, *}$ Rainer Adelung ${ }^{1, *}$ \\ ${ }^{1}$ Faculty of Engineering, Institute for Materials Science, Kiel University, Kaiserstr. 2, D-24143, Kiel, \\ Germany \\ ${ }^{2}$ Department of Microelectronics and Biomedical Engineering, Technical University of Moldova, 168 \\ Stefan cel Mare Av., MD-2004 Chisinau, Republic of Moldova
}

*Corresponding authors

Assoc.Prof. Lupan, Prof. Kienle Prof. Adelung

E-mails: ollu@tf.uni-kiel.de_ratt.uni-kiel.deratt.uni-kiel.de

Institute for Materials Science, Kiel University, Germany 
Figure S1
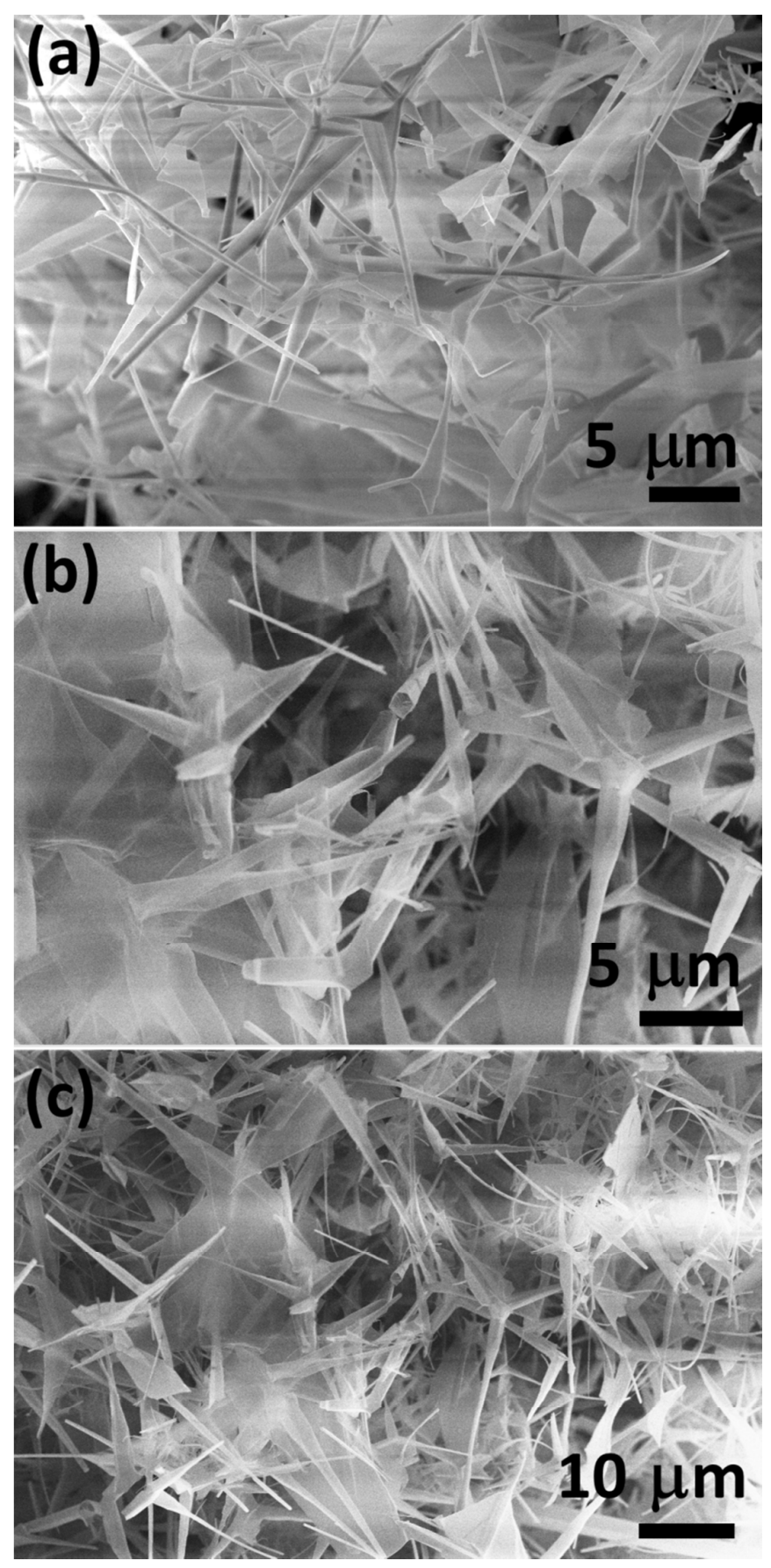

Figure S1. SEM images at different magnifications: (a-c) of the Si-T hollow tetrapods forming networks used for sensor fabrication. 
Figure S2

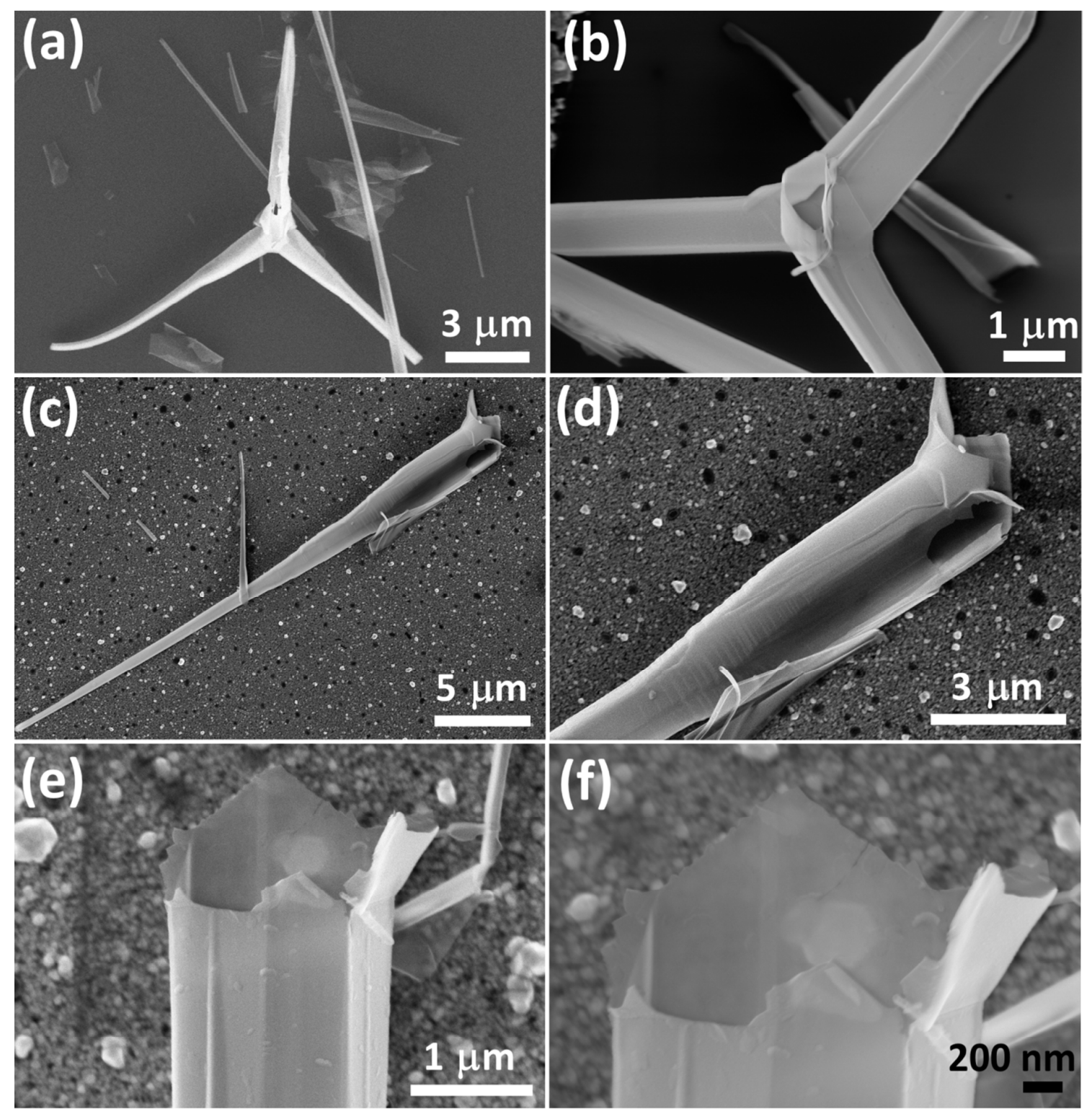

Figure S2. SEM images of the tetrapodal type structures from Set \#1(Si-T) transferred to $\mathrm{SiO}_{2} / \mathrm{Si}$ substrate with $\mathrm{Au} / \mathrm{Cr}$ electrical contacts: (a,b) hollow Si tetrapod arm at higher and lower magnification; (c,d) single Si-T arm at higher and lower magnification; (e,f) broken part of the Si-T arm at higher and lower magnification. 
Figure S3
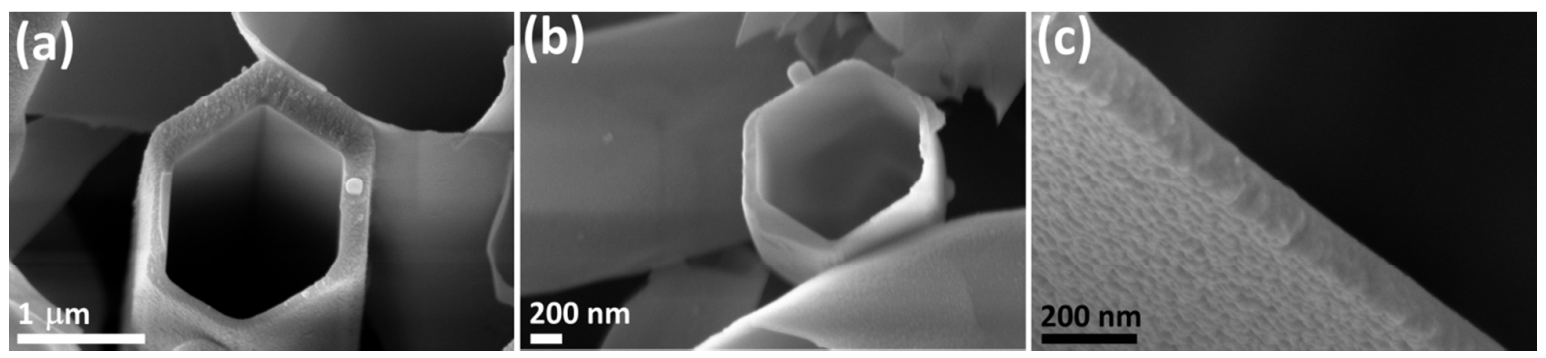

Figure S3. SEM images of a hollow Si tetrapod arm at high (a) and low (b) magnification from Set \#1(Si-T). (c) High magnification SEM image of a single Si wall for demonstrating of thickness and morphology.

Figure S4

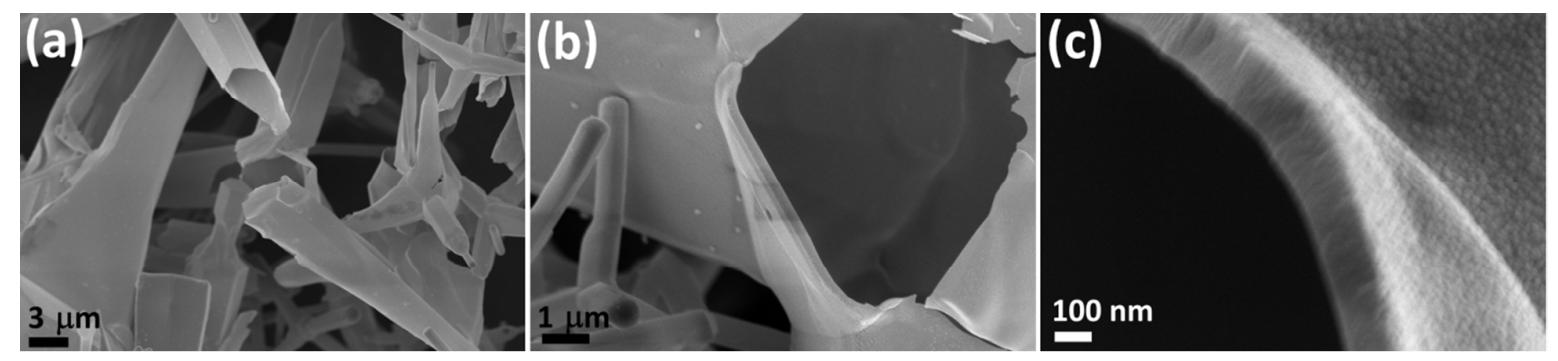

Figure S4. SEM images of a hollow Si tetrapod 3-D network at: (a) higher; and (b) lower magnifications from Set \#1 (Si-T). (c) High magnification SEM image of a Si tetrapod arm (Set \#1). 
Figure S5

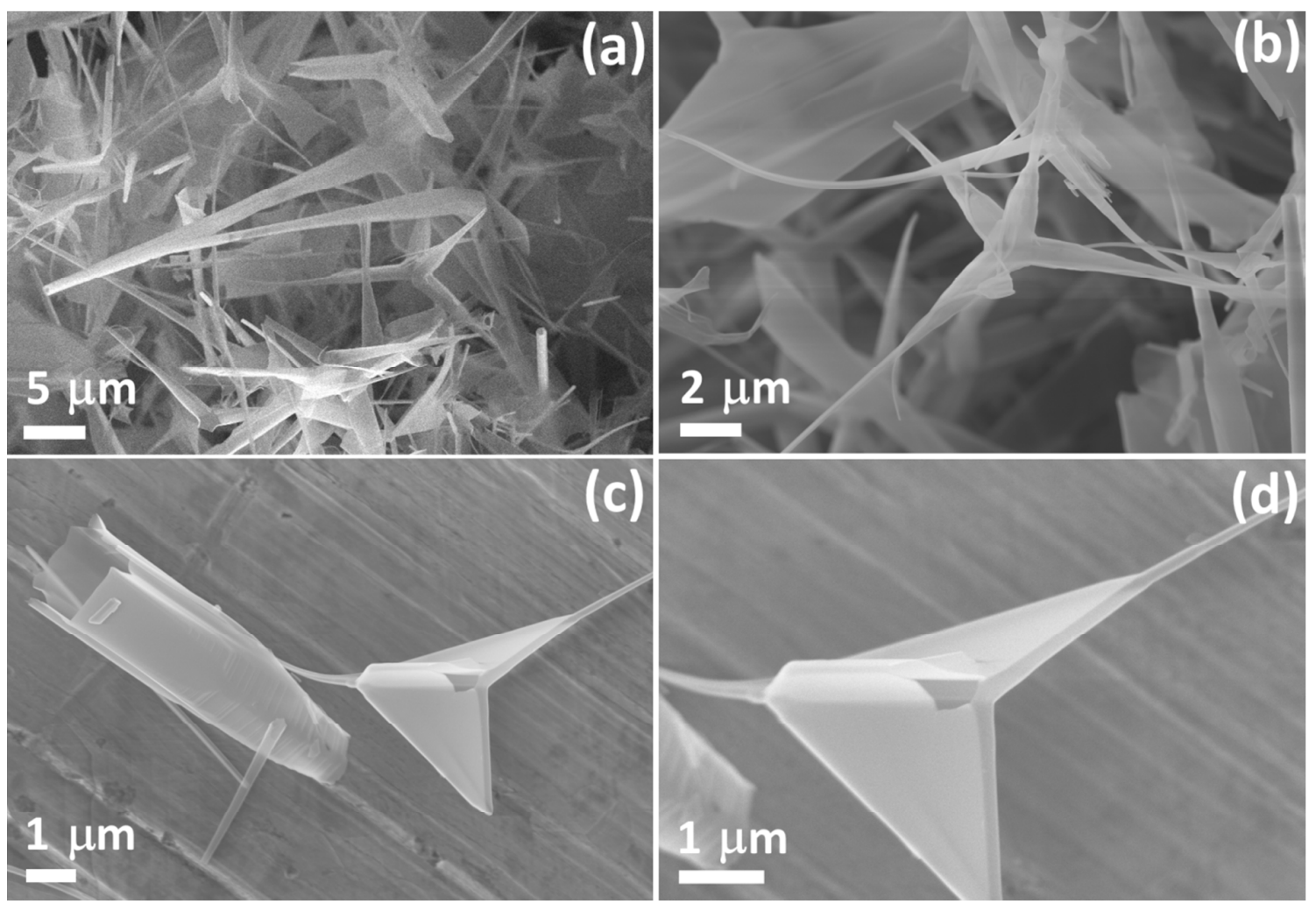

Figure S5. SEM images at different magnifications: (a-b) of the Si-T hollow tetrapods forming networks used for sensor fabrication; (c) differently shaped hollow Si architectures; (d) zoomed-in hollow "airplane" structure, showing that the developed nanotechnology can be applied to reproduce the most differently shaped nano- and microstructures as substrates. 


\section{Figure S6}

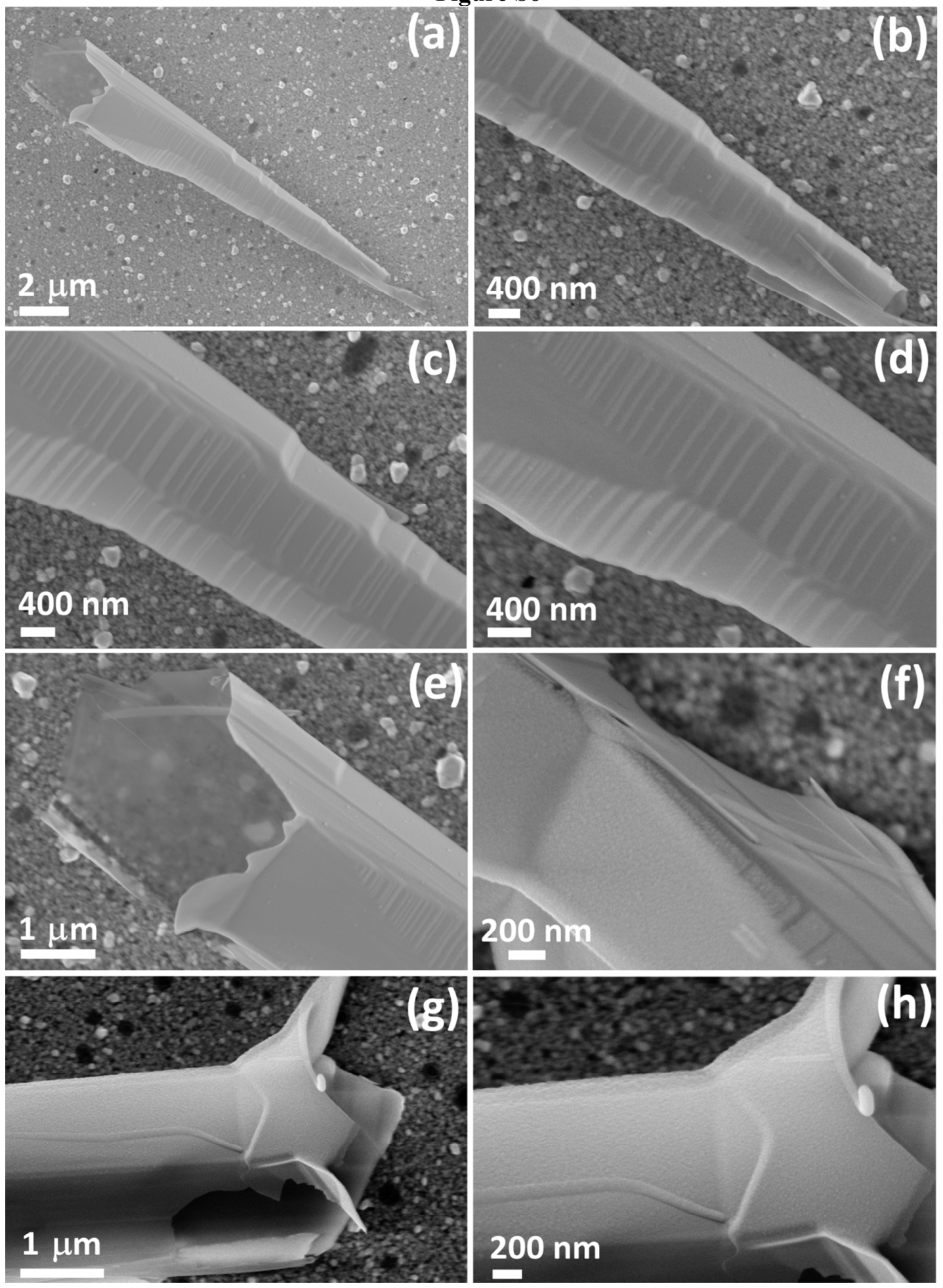

Figure S6. SEM images of a single Si-T arm: (a-d) in different magnifications; and (e-h) in different regions to demonstrate that the replicated structures resemble perfectly the initial shape and even the smallest morphological nano-details of the $\mathrm{ZnO}-\mathrm{T}$ arm can be replicated by developed sacrificial template approach. 
Figure S7

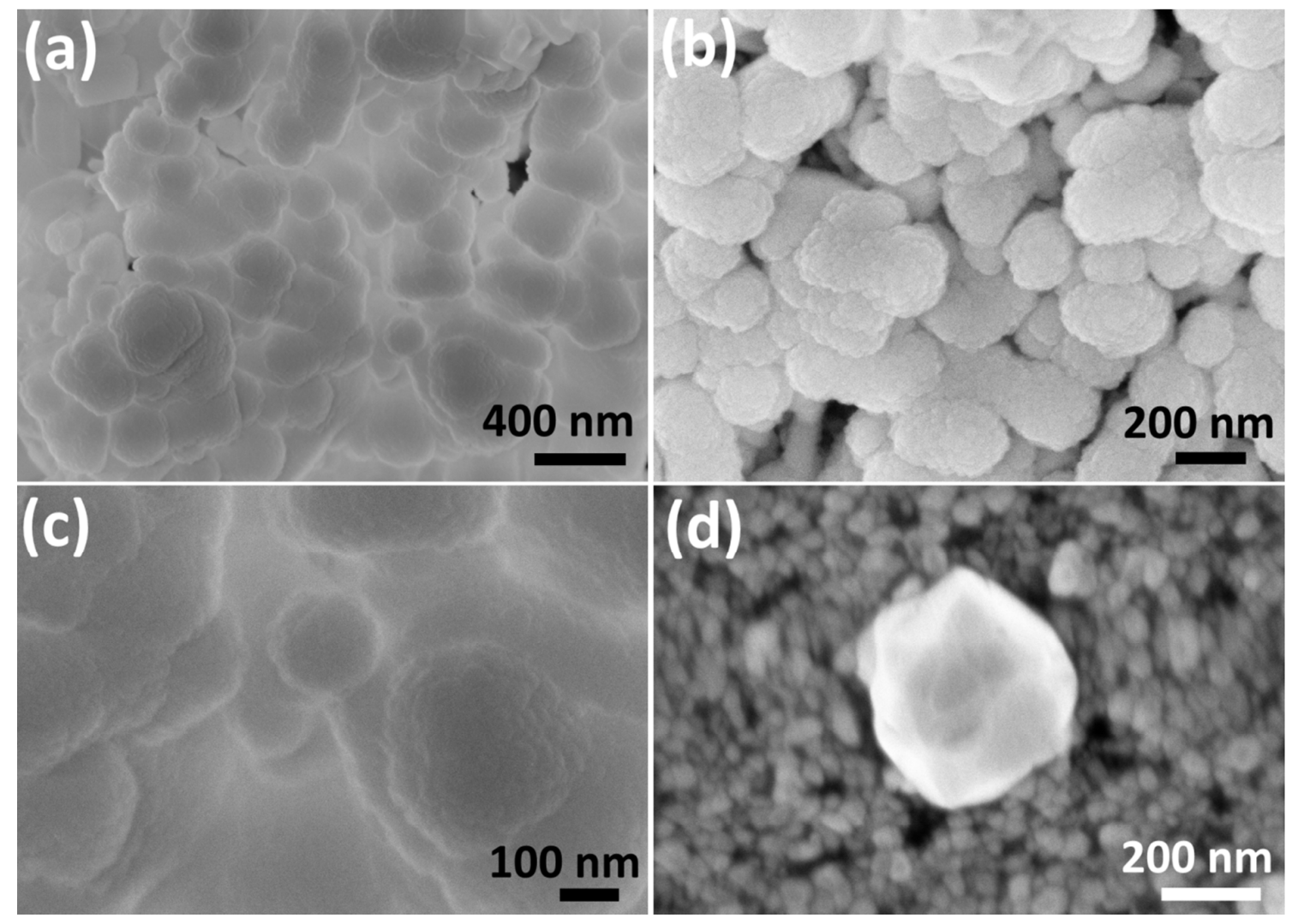

Figure S7. SEM images of the Si hollow microspheres: (a-c) at different magnifications; and (d) SEM image of a single $\mathrm{Si}$ microsphere transferred to $\mathrm{SiO}_{2} / \mathrm{Si}$ substrate with $\mathrm{Au} / \mathrm{Cr}$ electrical electrodes (small nanoparticles from the images represents deposited Au layer). 
Figure S8
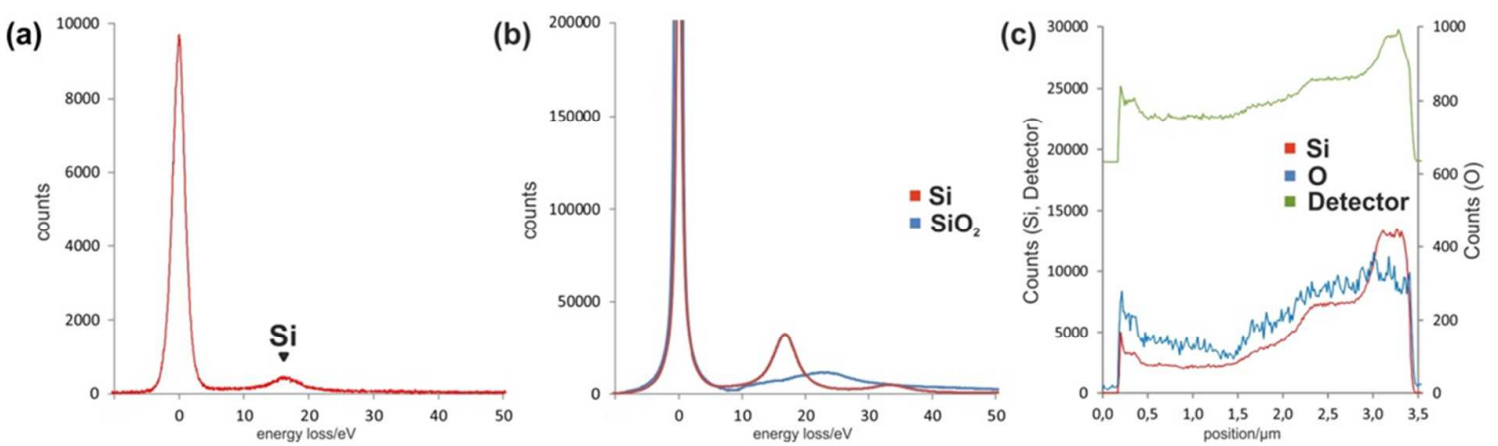

Figure S8. (a) EEL spectrum of a tetrapod containing the zero-loss peak and the plasmon peak of $\mathrm{Si}$ at $17 \mathrm{eV}$. (b) Reference EEL spectra for pure $\mathrm{Si}^{1}$ and $\mathrm{SiO}_{2}{ }^{2}$ (c) EDX-line scan profile for Si and O taken perpendicular across a tetrapods' arm.

Figure S9
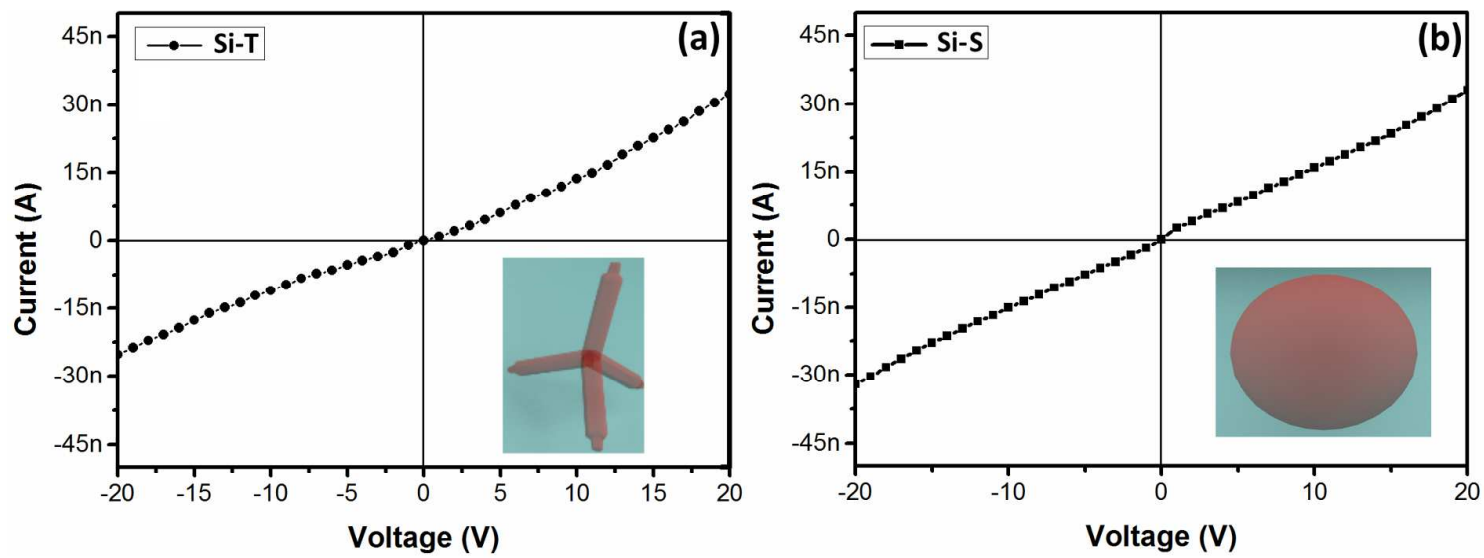

Figure S9. Current-voltage characteristics of the samples made from: (a) Set \#1; and (b) Set \#2 (Si-S). 
Figure S10

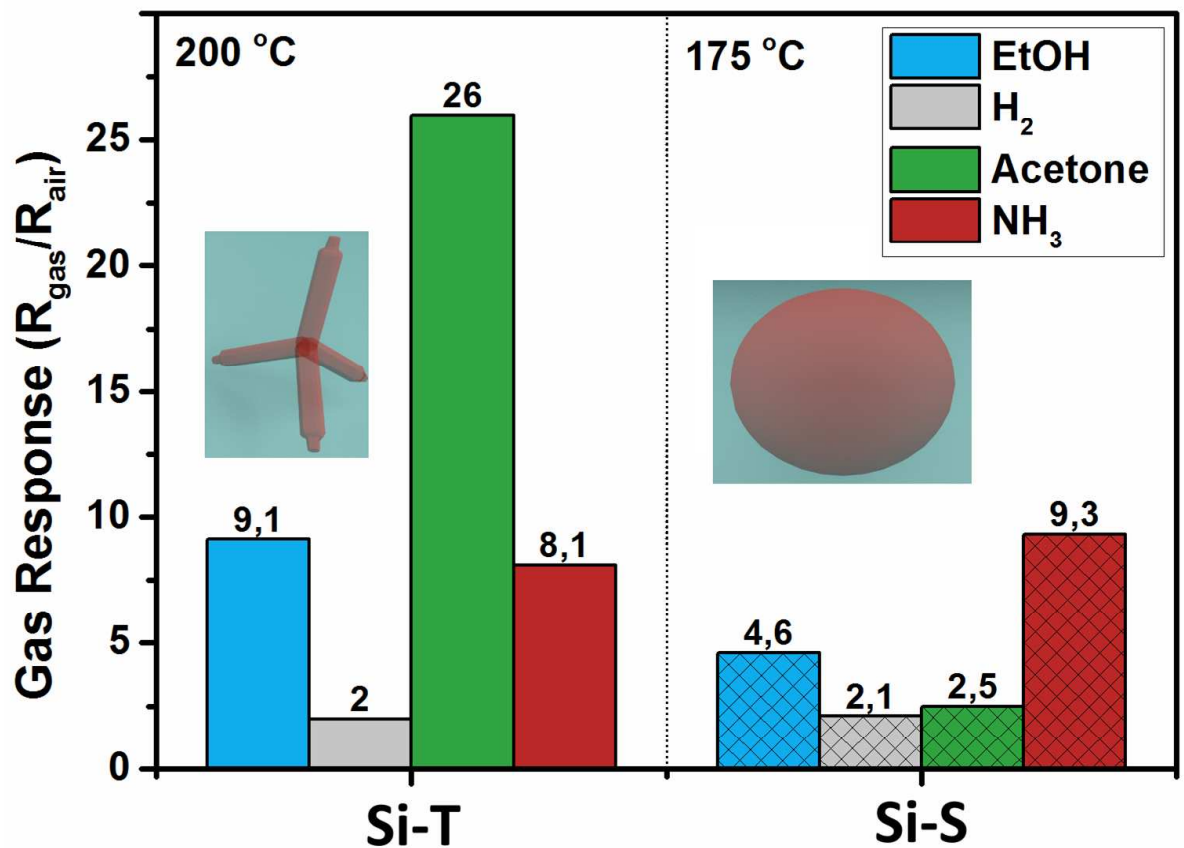

Figure S10. Gas response to acetone at $200{ }^{\circ} \mathrm{C}$ of the sensor based on samples made from Set $\# 1(\mathrm{Si}-\mathrm{T})$ and to $\mathrm{NH}_{3}$ at $175^{\circ} \mathrm{C}$ of the sensor based on samples from Set \#2(Si-T).

Figure S11

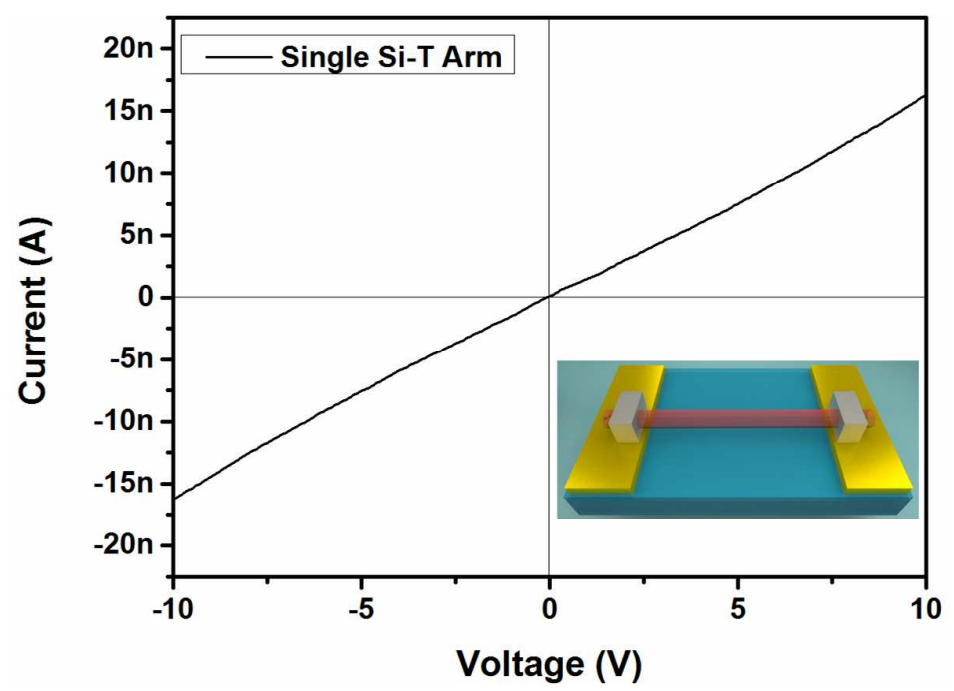

Figure S11. Current-voltage characteristic of the nanodevice based on single tetrapod Si-T arm (schematic is presented in inset). 
Figure S12

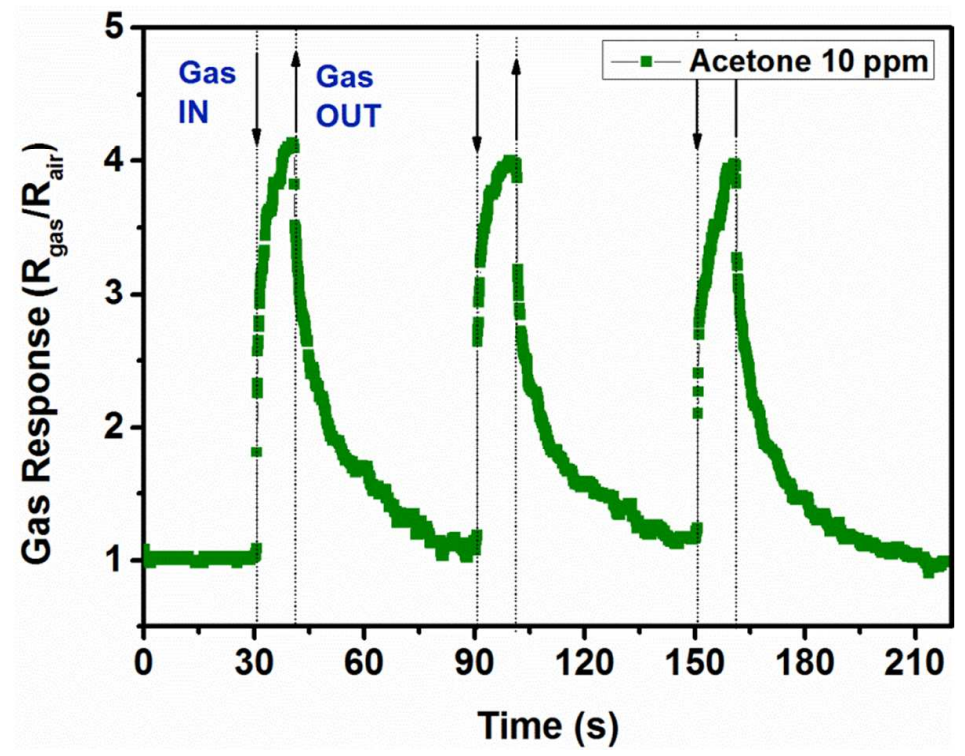

Figure S12. Dynamic response of the nanodevice based on single Si-T arm to $10 \mathrm{ppm}$ acetone at room temperature. 


\section{Figure S13}

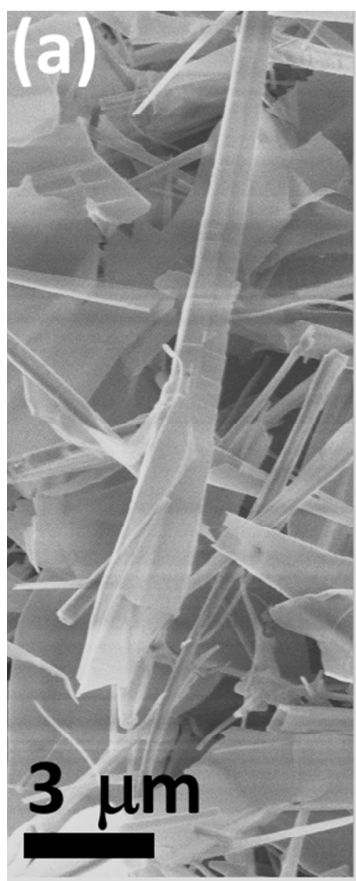

$3 \mathbf{k V}$

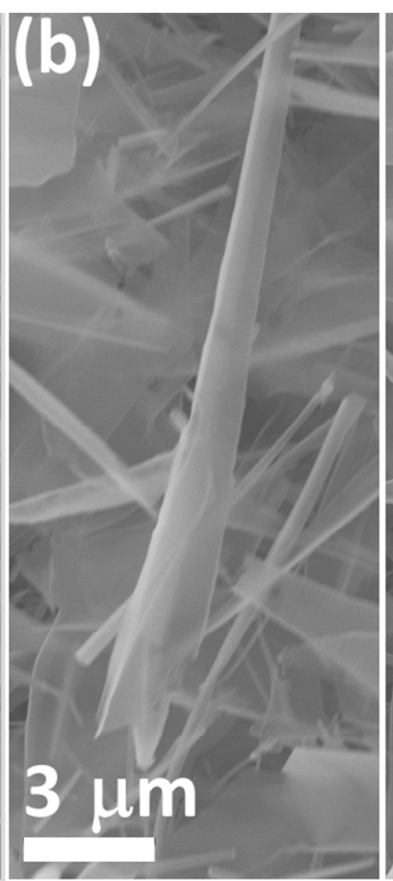

$10 \mathrm{kV}$

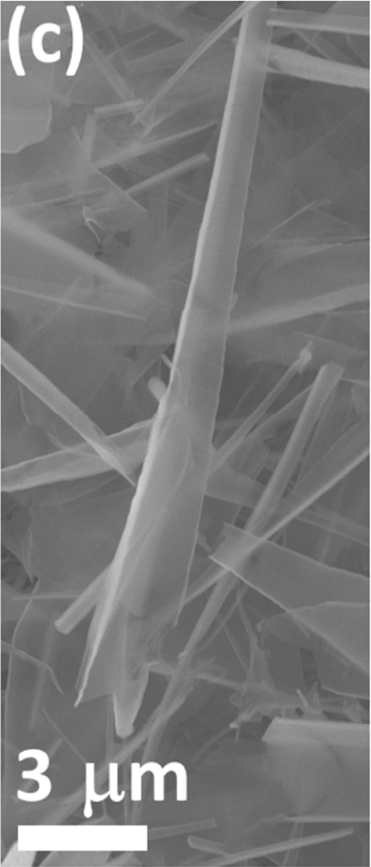

$15 \mathrm{kV}$

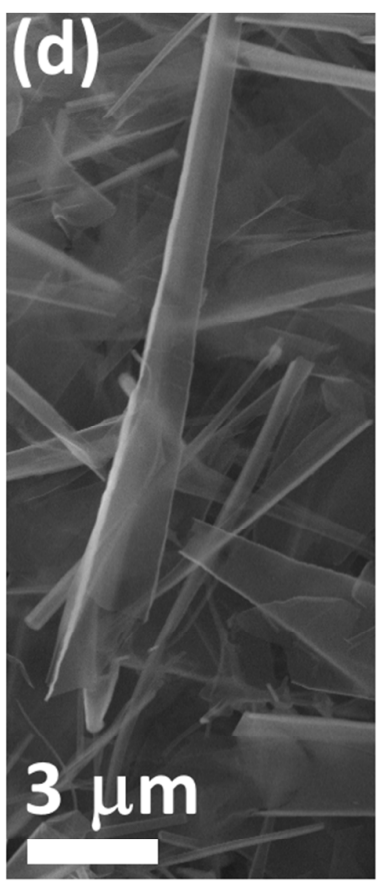

$20 \mathrm{kV}$

Figure S13. SEM images at different accelerating voltages in SEM: (a) $3 \mathrm{kV}$; (b) $10 \mathrm{kV}$; (c) $15 \mathrm{kV}$; (d) $20 \mathrm{kV}$. It shows that samples are hollow and transparent at higher voltages.

Figure S14

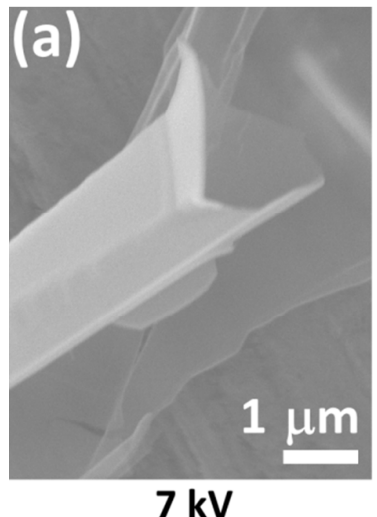

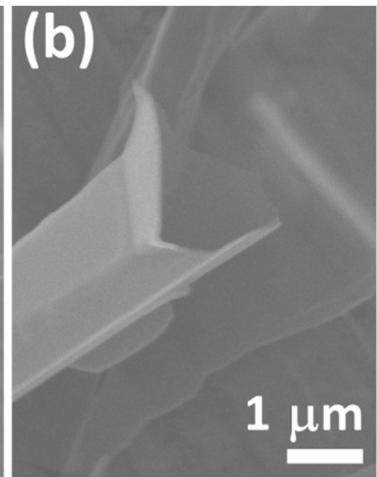

$12 \mathrm{kV}$

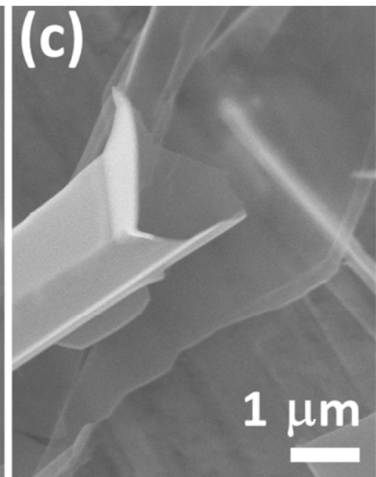

$15 \mathrm{kV}$

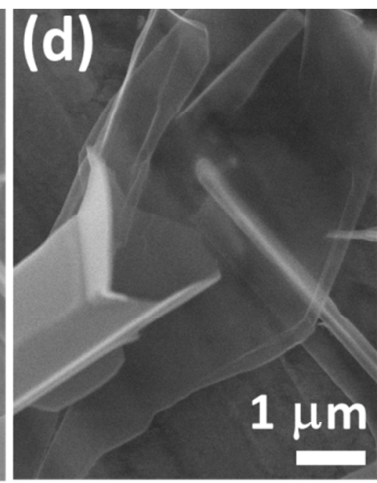

$20 \mathrm{kV}$

Figure S14. SEM images at different accelerating voltages of the electron beam. 


\section{Supporting Information Text S1 (Dependence of selectivity on morphology)}

In conclusion, samples from different sets demonstrated varying selectivity for biomedical application, i.e. Set \#1(Si-T) to acetone vapour and Set \#2 to $\mathrm{NH}_{3}$ vapour. However, samples from Set \#1(Si-T) are more selective than samples from Set \#2(Si-S). Thus, the selectivity depends on the morphology of the template (see Figure S8), which was confirmed by other investigations. For example Volanti et al. ${ }^{3}$ demonstrated that the morphology of $\mathrm{CuO}$ nanostructures has an influence on the gas diffusion and surface reaction effects resulting in different gas responses at the same conditions. Also, the shape and dimensions of nanostructures and the particle-to-particle contacts, forming energy potential barriers, have a major influence on the gas response. ${ }^{3-4}$ The effect of morphology on sensing properties of $\mathrm{ZnO}$ nanostructures was investigated by Rai et al., ${ }^{5}$ where it was demonstrated that the number of grains between interelectrode gaps has significant influence on the gas response. In the case of $\mathrm{SnO}_{2}$ the influence of different 1-D morphologies on the gas response was studied by Lingmin et al. ${ }^{6}$, and revealed that the gas response is dependent on the aspect ratio and the multimodel porosity of the 1-D nanostructures.

Thus, in our case the difference in selectivity of the hollow Si-T tetrapodal 3-D networks and hollow Si-S microspheres can be explained by different gas diffusion processes and surface reaction effects. In the case of $\mathrm{Si}-\mathrm{T}$ hollow tetrapod 3-D networks the porosity of the sensing layer is higher than in case of Si-S hollow spheres, due to anti-agglomeration properties of the tetrapod 3-D networks. ${ }^{7}$ Additionally, they allow faster diffusion rates of test gas, and a higher number of nanostructures from the interior of sensing layer can participate in the gas sensing

process..$^{8}$ As a result, a higher gas response can be obtained, ${ }^{3-5}$ which is demonstrated in Figure S8 and Figure 3c,d. In accordance to the gas-diffusion theory, the molecular gas diffusion rate will be higher due to the relatively big openings in the tetrapods. This allows the 
inner part of the tetrapod walls to participate to surface chemical reactions which can provide more gas diffusion. ${ }^{8}$ 


\section{Supporting Information Text S2 (Gas sensing mechanism proposed for Si-T)}

The gas sensing mechanism can be explained as following. Jie et al. ${ }^{9}$ demonstrated that electrical transport in Si NWs strongly depend on surface phenomena and ambient. Due to the rough surface of silicon in both type of samples (Set \#1, Si-T, and Set \#2, Si-S, see Figure 1, S1-S5) a high concentration of trapping states may be present on the sample surface, due to surface defects and charges. ${ }^{9}$ Therefore, mainly water molecules are adsorbed on the surface of silicon samples, forming $\mathrm{OH}^{-}$species and trapping electrons from the conduction band and forming a hole accumulation layer (HAL) on the surface of $p$-type silicon, or electron depleted region on the surface of $n$-type silicon. ${ }^{9-10}$

The gas molecules can influence the resistivity of the silicon nanostructures mainly in two ways. First is the modulation of the contact resistance between two silicon nanostructures (Si$\mathrm{T}$ or $\mathrm{Si}-\mathrm{S}$ ) and second is the resistance modulation of individual silicon nanostructure due to band bending at the surface as a result of $\mathrm{OH}^{-}$species adsorption. ${ }^{9,}$ 11-12 Thus, potential barriers sensitive to gas species and vapor, which will increase the gas response of the sensors may be forming between hollow $\mathrm{Si}-\mathrm{T}$ arms or Si-S. ${ }^{7-8}$ Also, the $\mathrm{NH}_{3}$ vapor may act as a chemical gate, which shifts the Fermi levels of the silicon nanostructures and modulates the resistance of the samples. ${ }^{11,13}$ 
Table S1. Calculated parameters for sensor structures based on aero-silicon, Si-T and Si-S, grown by developed sacrificial template nanotechnology

\begin{tabular}{|l|l|l|l|c|c|}
\hline Sample type & $\begin{array}{l}\text { Operating } \\
\text { temperature } \\
\left({ }^{\mathbf{0}} \mathbf{C}\right)\end{array}$ & Gas/vapor & $\begin{array}{l}\text { Gas } \\
\text { response } \\
\left(\mathbf{R}_{\text {gas }} / \mathbf{R}_{\text {air }}\right)\end{array}$ & $\begin{array}{l}\text { Response } \\
\text { time (s) }\end{array}$ & $\begin{array}{l}\text { Recovery } \\
\text { time (s) }\end{array}$ \\
\hline $\begin{array}{l}\text { 3-D hollow Si- } \\
\text { T networks }\end{array}$ & 200 & Acetone 100 ppm & $\sim 26$ & 16 & 7 \\
\hline $\begin{array}{l}\text { Hollow Si-S, Si } \\
\text { microspheres } \\
\text { forming } \\
\text { networks }\end{array}$ & 175 & $\mathrm{NH}_{3} 50 \mathrm{ppm}$ & $\sim 10$ & 18 & 9 \\
\hline $\begin{array}{l}\text { Single Si-T arm } \\
\text { based } \\
\text { nanosensor }\end{array}$ & $\mathrm{RT}$ & $\begin{array}{l}\text { Acetone 100 ppm } \\
\text { Acetone 10 ppm }\end{array}$ & & & \\
\hline
\end{tabular}

Table S2. $\mathrm{NH}_{3}$ sensors based on silicon and semiconducting oxides nanostructures for comparison reasons

\begin{tabular}{|c|c|c|c|c|c|c|}
\hline $\begin{array}{l}\text { Morphology and properties } \\
\text { of sensing material }\end{array}$ & $\begin{array}{l}\mathrm{NH}_{3} \\
\text { conc. } \\
(\mathrm{ppm})\end{array}$ & $\begin{array}{l}\text { Gas response } \\
\left(R_{\mathrm{g}} / R_{\mathrm{a}}\right)^{\mathrm{a})} \text { or } \\
\left(R_{\mathrm{a}} / R_{\mathrm{g}}\right)^{\mathrm{b})}\end{array}$ & $\begin{array}{l}\text { Operating } \\
\text { temp. }\left({ }^{\circ} \mathrm{C}\right)\end{array}$ & $\begin{array}{l}\text { Response } \\
\text { time }\end{array}$ & $\begin{array}{l}\text { Recovery } \\
\text { time }\end{array}$ & Ref. \\
\hline $\begin{array}{l}\text { Si NWs network } \\
\text { Polysilicon Si NWs resistor }\end{array}$ & $100 \%^{c)}$ & $\begin{array}{l}\sim 20 \\
\sim 100\end{array}$ & RT & $\begin{array}{l}\sim 1 \min ^{\mathrm{d})} \\
\sim 2 \min ^{\mathrm{d})}\end{array}$ & $\begin{array}{l}\sim 3 \min ^{\mathrm{d})} \\
\sim 1 \min ^{\mathrm{d})}\end{array}$ & 12 \\
\hline Porous silicon & 100 & $\sim 20$ & RT & $\sim 5 \mathrm{~s}$ d) & $\sim 36 \mathrm{~s}$ d) & 14 \\
\hline $\begin{array}{l}\text { Single-wall nanotube } \\
\text { (SWNT) }\end{array}$ & 10000 & $\sim 10-100$ & RT & $\sim 1-2 \mathrm{~min}$ & $\sim 12 \mathrm{~h}$ & 13 \\
\hline Te-modified Si NWs & 100 & $\sim 2^{\text {d) }}$ & RT & $5 \mathrm{~s}$ & $8 \mathrm{~s}$ & 15 \\
\hline Hierachical $\mathrm{Co}_{3} \mathrm{O}_{4}$ nanorods & 100 & $\sim 11$ & 160 & $1-4 \mathrm{~s}$ & $4-13 \mathrm{~s}$ & 16 \\
\hline $\mathrm{SnO}_{2}$ hierachical NWs & 500 & $\sim 11$ & 200 & $16 \mathrm{~s}$ & $25 \mathrm{~s}$ & 17 \\
\hline $\mathrm{SnO}_{2}$ nanoparticles & 60 & $\sim 6$ & 300 & $100 \mathrm{~s}$ & - & 18 \\
\hline $\mathrm{SnO}_{2}$ nanorods film & 500 & $\sim 20$ & 200 & $>10 \min ^{\mathrm{d})}$ & $>10 \min ^{\mathrm{d})}$ & 19 \\
\hline $\begin{array}{l}\text { Au-loaded } \mathrm{ZnO} \text { hollow } \\
\text { nanospheres }\end{array}$ & 50 & $\sim 65$ & 240 & $\sim 1 \mathrm{~s}$ & $3 \mathrm{~s}$ & 20 \\
\hline Hollow Si-S 3-D networks & 50 & $\sim 10$ & 175 & 18 & 9 & $\begin{array}{l}\text { This } \\
\text { work }\end{array}$ \\
\hline
\end{tabular}

${ }^{a}$ Gas response for $p$-type semiconducting oxides; ${ }^{b)}$ Gas response for $n$-type semiconducting oxides; ${ }^{\text {c) }}$ Arbitrary ammonia pressure of 200 mbar of pure ammonia in the test chamber without any carrier gas; ${ }^{\mathrm{d}}$ Denotes a value approximated from a graphical plot. 


\section{References}

(1) Batson, P. E. Current Trends for EELS Studies in Physics. Microsc. Microanal.

Microstruct. 1991, 2, 395-402.

(2) Schamm, S. eelsd.eu. eelsd.eu 2007.

(3) Volanti, D. P.; Felix, A. A.; Orlandi, M. O.; Whitfield, G.; Yang, D. J.; Longo, E.; Tuller, H. L.; Varela, J. A. The Role of Hierarchical Morphologies in the Superior Gas Sensing Performance of $\mathrm{CuO}$ - Based Chemiresistors. Adv. Funct. Mater. 2013, 23, 1759-1766.

(4) Barsan, N.; Simion, C.; Heine, T.; Pokhrel, S.; Weimar, U. Modeling of Sensing and Transduction for p-type Semiconducting Metal Oxide based Gas Sensors. J. Electroceram. 2010, $25,11-19$.

(5) Rai, P.; Kwak, W.-K.; Yu, Y.-T. Solvothermal Synthesis of ZnO Nanostructures and Their Morphology-Dependent Gas-Sensing Properties. ACS Appl. Mater. Interfaces 2013, 5, 30263032.

(6) Lingmin, Y.; Xinhui, F.; Lijun, Q.; Lihe, M.; Wen, Y. Dependence of Morphologies for $\mathrm{SnO}_{2}$ Nanostructures on Their Sensing Property. Appl. Surf. Sci. 2011, 257, 3140-3144.

(7) Mishra, Y. K.; Modi, G.; Cretu, V.; Postica, V.; Lupan, O.; Reimer, T.; Paulowicz, I.; Hrkac, V.; Benecke, W.; Kienle, L. Direct Growth of Freestanding ZnO Tetrapod Networks for Multifunctional Applications in Photocatalysis, UV Photodetection, and Gas Sensing. ACS Appl. Mater. Interfaces 2015, 7, 14303-14316.

(8) Wang, X.; Wang, Y.; Tian, F.; Liang, H.; Wang, K.; Zhao, X.; Lu, Z.; Jiang, K.; Yang, L.; Lou, X. From the Surface Reaction Control to Gas-Diffusion Control: The Synthesis of Hierarchical Porous $\mathrm{SnO}_{2}$ Microspheres and Their Gas-Sensing Mechanism. J. Phys. Chem. C 2015, 119, 15963-15976.

(9) Jie, J.; Zhang, W.; Peng, K.; Yuan, G.; Lee, C. S.; Lee, S. T. Surface - Dominated Transport Properties of Silicon Nanowires. Adv. Funct. Mater. 2008, 18, 3251-3257. 
(10) Cui, Y.; Wei, Q.; Park, H.; Lieber, C. M. Nanowire Nanosensors for Highly Sensitive and Selective Detection of Biological and Chemical Species. Science 2001, 293, 1289-1292.

(11) Zhou, X.; Hu, J.; Li, C.; Ma, D.; Lee, C.; Lee, S. Silicon Nanowires as Chemical Sensors. Chem. Phys. Lett. 2003, 369, 220-224.

(12) Demami, F.; Ni, L.; Rogel, R.; Salaun, A.-C.; Pichon, L. Silicon Nanowires Based Resistors as Gas Sensors. Sens. Actuators B 2012, 170, 158-162.

(13) Kong, J.; Franklin, N. R.; Zhou, C.; Chapline, M. G.; Peng, S.; Cho, K.; Dai, H. Nanotube Molecular Wires as Chemical Sensors. Science 2000, 287, 622-625.

(14) Li, M.; Hu, M.; Zeng, P.; Ma, S.; Yan, W.; Qin, Y. Effect of Etching Current Density on Microstructure and $\mathrm{NH}_{3}$-Sensing Properties of Porous Silicon with Intermediate-Sized Pores. Electrochim. Acta 2013, 108, 167-174.

(15) Yang, L.; Lin, H.; Zhang, Z.; Cheng, L.; Ye, S.; Shao, M. Gas Sensing of TelluriumModified Silicon Nanowires to Ammonia and Propylamine. Sens. Actuators B 2013, 177, 260-264.

(16) Deng, J.; Zhang, R.; Wang, L.; Lou, Z.; Zhang, T. Enhanced Sensing Performance of the $\mathrm{Co}_{3} \mathrm{O}_{4}$ Hierarchical Nanorods to $\mathrm{NH}_{3}$ Gas. Sens. Actuators B 2015, 209, 449-455.

(17) Van Hieu, N. Comparative Study of Gas Sensor Performance of $\mathrm{SnO}_{2}$ Nanowires and Their Hierarchical Nanostructures. Sens. Actuators B 2010, 150, 112-119.

(18) Choi, K.-Y.; Park, J.-S.; Park, K.-B.; Kim, H. J.; Park, H.-D.; Kim, S.-D. Low Power Micro-gas Sensors using Mixed $\mathrm{SnO}_{2}$ Nanoparticles and MWCNTs to Detect $\mathrm{NO}_{2}, \mathrm{NH}_{3}$, and Xylene Gases for Ubiquitous Sensor Network Applications. Sens. Actuators B 2010, 150, 6572.

(19) Wang, L.; Lou, Z.; Fei, T.; Zhang, T. Templating Synthesis of ZnO Hollow Nanospheres Loaded with Au Nanoparticles and Their Enhanced Gas Sensing Properties. J. Mater. Chem. 2012, 22, 4767-4771. 
(20) Forleo, A.; Francioso, L.; Capone, S.; Casino, F.; Siciliano, P.; Tan, O. K.; Hui, H.

Fabrication at Wafer Level of Miniaturized Gas Sensors Based on $\mathrm{SnO}_{2}$ Nanorods Deposited by PECVD and Gas Sensing Characteristics. Sens. Actuators B 2011, 154, 283-287. 